\title{
Logistics Development in Malaysia East Coast Region: Infrastructure, Constraints and Challenges
}

\author{
A. A. Zuraimi, Mohd Rafi Yaacob, and Mohamed Dahlan Ibrahim
}

\begin{abstract}
This paper examines the current logistics development in the East Coast Region of Peninsular Malaysia. Malaysia as well as other developing countries are still at the moderate stage in developing logistics systems and often face considerable challenges and constraints to provide efficient and effective logistics service. This research is based on survey conducted in the region. The respondents were from the different logistics players and stakeholders. Altogether there were 41 usable questionnaires were analyzed. In general the results reveal logistic players satisfied with the current logistics infrastructures in the region. However, further analysis found organizations that have been operated more than 10 years neither satisfied nor dissatisfied with the current logistics infrastructures. In addition this study found a couple of constraints and challenges in the logistics industry and amongst them were professionalism in supporting the development, skill of manpower and financial issues within organizations deal with logistics.
\end{abstract}

Index Terms-Challenges, constraints, infrastructure, logistics development.

\section{INTRODUCTION}

East Coast Economic Region (ECER) was established by the government of Malaysia as one of Malaysia economic corridors within the East Coast Region (ECR). Apart from ECER, there are four others regional economic corridors in Malaysia namely; Iskandar Regional Development Authority (IRDA), Northern Corridor Economic Region (NCER), Sabah Development Corridor (SDC) and Sarawak Corridor of Renewable energy (SCORE) [1]. The purpose of ECER establishment is to effectively transform the under-developed region into a major international business activities as well as to beef up local business activities, covering the exporter of natural resources based and a small extent of manufactured products, a vibrant trading centre, and an infrastructure and logistics hub. In terms of geography, ECER is strategically located; it is near to booming areas of Vietnam, Thailand, Cambodia as well as China. Thus, the ECER has the potential to become the main gateway for trade and industry within the Asia Pacific region [2].

The ECER covers the whole coastal areas in Peninsular Malaysia, involves the states of Kelantan, Terengganu and Pahang, as well as the district of Mersing in Johor. With an area measuring more than $66,000 \mathrm{sq} \mathrm{km}$, the ECER covers

Manuscript received June 20, 2013; revised August 25, 2013. This work was supported by the Universiti Malaysia Kelantan under the Short Grant Research Scheme.

The authors are with the Faculty of Entrepreneurship and Business, Universiti Malaysia Kelantan, 16100 Kota Bahru, Kelantan, Malaysia (e-mail: rafi@umk.edu.my,dahlan@umk.edu.my). more than half of Peninsular Malaysia. The ECER's population of about 3.9 millions represents $14.5 \%$ of the total population of Malaysia. Five economic clusters have been identified as key focal points for development in the ECER such as i) Tourism, ii) Oil, gas and petrochemical, iii) Manufacturing, iv) Agriculture and v) Education. In order to fast track the setting up of ECER Master Plan, the East Coast Economic Region Special Economic Zone (ECER SEZ) has been launched which covers the 6 key economics drivers such as high-value manufacturing; agro-based industry; oil, gas and petrochemical; tourism/real estate; knowledge/education \& information, communication and technology (ICT); and logistics [2].

With regards to logistics, it has assumed a very prominent role as it provides the backbone of economic growth in the region and to facilitate international trade to tap available opportunities of booming economy of neighbouring countries and the Far East. It is one of the key service offerings required in the business environment today and a driver of growth in developing economies. As it has being one of the catalysts for the development of industrialization in Malaysia, the performance of this industry will have an impact of the nation's industrialization and its competitiveness in international trade. Thus, the existence of conducive logistics development in this region helps the expansion of the above mentioned industries. Indeed, the improvement of logistics systems in ECR can provide a foundation for further economic development and integration within the areas of the region.

Notwithstanding with the importance of efficient and effective logistics systems, however, there has been very little published research in the area in Malaysia and other developing countries; resulting very limited information could be gathered on the patterns of logistics development in the recent years. The importance of efficient logistics for trade and growth is now widely acknowledged. Therefore, in light of the above, the objectives of this paper are: i) to examine the current logistics infrastructures in the ECR, ii) to find out the constraints and iii) to know the challenges in logistics development.

\section{LiterATURE REVIEW}

\section{A. Logistics Infrastructure}

The development of logistics infrastructure has been a key factor in trade integration [3]. It would be a fundamental factor in the operation of logistics networks through integrating of maritime, air and land transport mode. Furthermore, logistics infrastructure would be important to the country attractiveness in terms of attracting potential investor from both domestic and international to set up new 
or expand its business activities. In developed countries, ports, and especially the logistics platform have played an important role in facilitating the trade activities. This is because most of global trade involves maritime traffic and it requires integration between maritime and road traffic as well as rail transportation. For example, Germany as reported by [4] has been one most attractive location for distribution centers. Germany has an excellent road systems, waterways and rail networks, an extensive network of freight villages and intermodal facilities includes rail-road, water-road, water-rail-road equipped with rolling road terminals; airports, seaports and inland ports.

However, the developing countries including Malaysia are still struggling in providing the sufficient logistics infrastructure. For example, infrastructure capacity in China is unbalanced although strong exports in past two decades have stimulated the infrastructural development in China important coastal regions [5]. Despite the increase in highway length in the country, the rate of increase in highway length is generally much slower than the rate of increase in highway freight volume [6]. With regards to Malaysia, especially in the West Coast of Peninsular Malaysia, major Malaysian ports have both road and rail access but the quality of the connectors need to be improved [7], [8].

The most developed industrial areas in the ECR are Pahang and Terengganu. Both states supported by two ports i.e. Kuantan Port and Kertih Terminal; and one supply base which is Kemaman Supply Base (KSB). In these areas, logistics systems play a very crucial role to ensure that the businesses run smoothly, especially for import and export activities. However, Kelantan is lagging behind the both areas, is now developing the industrial areas such as the supply base and soon to be a seaport in operation namely Portokbali which was launched in March 2012 to accommodate the logistics activities to cater export of minerals including ores and oil and gas to Far East countries.

As far as the road transport network is concerned, second phase of East Coast Expressway to connect Kuala Terengganu, Terengganu and Kuantan, Pahang is being implemented and it will be followed up by the third phase projection to Kelantan. Kuantan is already connected to Kuala Lumpur through the first phase of this project [2]. With the completion of East Coast Expressway, efficient road transport network is expected within the ECR region. As for the railway operations in this region, there is cargo service rendered by Keretapi Tanah Melayu Berhad (KTMB) but in the small volume and only limited for port inland. Majority of railway operations are to cater for passengers who commuted from city to city in hinterland of Kelantan and Pahang [9]. Each area has it owns airport, but only Terengganu airport enjoys international airport status. Nevertheless, small volumes of cargo services are handled as compared to the passengers. In addition, there are warehousing facilities offered by the both Kuantan port and $\mathrm{KSB}$ for the logistics player in this region.

\section{B. Logistics Constraints}

Previous study [10] found several constraints of logistics and supply chains in Malaysia, amongst others; problems in information technology (IT) system with regard to the costly
Electronic Data Interchange (EDI) pricing and charges due to in transparent marks-up by freight forwarders, lack of follow up actions after certain meetings or issues raised, lack of sophisticated management techniques among the supply chain companies, and overall performance and functionality of the system, lack of skilled and trained manpower, no single established source of logistics data and information including lack of information of the industry players, facilities, services and capabilities of the sectors, lack of research and development of the industry, lack of regulatory forms to facilitate the industry, and lack of dissemination of information with regard to the development and expansion of the logistics industry.

A study conducted by [5] in China, it was found that human resource is one of the constraints where the demand for talent outstripped supply in the logistics industry. Logistics cost also the constraints as the proportion of the logistics cost to total production cost is estimated at $20-30 \%$ in China, compared to only $10 \%$ in the developed countries [11]. Other major logistics barriers in China included; the lack of responsiveness and dependability of local suppliers, inadequate communications infrastructure, complicated and time-consuming customs procedures and the unavailability of logistics consulting services [12].

Even in Singapore which is far ahead of other Asian countries faces some constraints in transport and logistics systems in term of high cost of operations (especially land rental and wages), small geographic space and domestic market, industry was fragmented and lacks scale with very few global players with global aspirations, instances of lack of logistics clusters, lack of responsiveness of customers' needs, shortage of skilled, experienced and entrepreneurial logistics professionals and inadequate technological capabilities to carry out wide range of logistics and supply chain management [13].

\section{Logistics Challenges}

A study by [14] highlighted unclear communication between Logistics Service Providers (LSPs) and users lead to business interruption is one of the challenges. Both LSPs and shippers have to form the partnership to create more values for both parties. This is because both parties have their own objectives to resolve the problem whereby LSPs are now experiencing unstable growth and shippers are facing constant pressure to lower their operational cost and increase efficiency and effectiveness [15]. On the other hand, [16] reported in the fifth state of logistics survey that the increasing logistics cost in South Africa continues to be constraints and challenges to expand market into international trade. The survey reported that this country's logistics cost were $14 \%$ higher compared to the other countries. The main reasons are being far away from all sources of imports, and relying heavily on road transport rather than rail transportation.

Even various industries in China grows year of year due to her economic booming that cater burgeoning demand worldwide, there were also some major challenges that interrupt the development like rising cost, financing bottlenecks, in-house mindsets to handle logistics, localized services, lack of unified top level institutional coordination and imbalance transport infrastructure development [5]. 
Other challenges in China as reported by [17] were poor infrastructure, regulation, bureaucracy and culture, poor training, ICT, undeveloped domestic industry, high transport costs, poor warehousing and storage, regional imbalance and domestic trade barriers. In addition, $[14,18]$ mentioned the recruiting and retaining good staff can be big challenges as there is a considerable lack of skills amongst candidates.

\section{RESEARCH METHOD}

The primary data were obtained through a survey using self-administered questionnaire through mail. The survey questionnaire consists of three sections with the five-point Likert-scale questions to provide numerical data on the dimensions of variables. The respondents were asked to choose answers ranging from " 1 " describing "Strongly Disagree" to "5" being "Strongly Agree".

Section one in the questionnaire covered the demographic part. In this section the classification of organization respondents were based on five clusters; i) local authority, ii) manufacturer, iii) LSPs, iv) port operator and v) other logistics users. Other logistics users in this study were defined as any other users relate to the logistics activities. Section two emphasized the current logistics infrastructures owned by the organization and infrastructures provided by the government. Items for logistics infrastructures were regarding well maintained (WM), infrastructure distribution (ID), smooth deliver (SD), road access (RA1), rail access (RA2), sea access (SA), warehousing access (WA), road good condition (GD), traffic condition (TD) and sharing with public users (SR).

Section three is sought information about the constraints of logistics industry in this region. Items for constraints comprised lack of infrastructure (LI), lack of research (LR), lack of professionalism (LP), lack of access to financial (LF) and government policy (GP). In the last section of questionnaire, the respondents were asked on the challenges faced by the respondents in order to develop effective and efficient of logistics development. Items for challenges were; cost of logistics (COS), unclear communication (COM), manpower skill (MAN), user's attitude (ATT) and small market (MKT).

Altogether, 132 respondents were purposive sampled from the company located within the ECR of Peninsular Malaysia. Only 41 or $31.07 \%$ of the survey questionnaires were returned and used for the final analysis. The data were analyzed using SPSS Version 19.

From the analysis, it was identified that the Cronbach alpha of all constructs were between $0.79-0.81$ as shown in Table I.

TABLE I: RELIABILITY TEST

\begin{tabular}{lll}
\hline Dimensions & Items & Cronbach Alpha \\
\hline Logistics Infrastructure & 10 & 0.79 \\
Logistics Constraint & 5 & 0.80 \\
Logistics Challenge & 5 & 0.81 \\
\hline
\end{tabular}

Generally, the reliability coefficient indicates that there was a high level of consistency in the responses given by the respondents [19]. According to [20] a reliability coefficient of 0.70 and above levels considered more than acceptable for most behavioral science applications. This reliability test is important because it is related to the validity concept, which is to prove that the instrument used is consistent, stable, and predictable and will yield correct results without room for doubt [21]. Thus, the instrument used in this study showed a good level in terms of reliability.

\section{RESUlTS AND DisCUSSION}

\section{A. Profiles of Organizations}

The profiles of respondents' organization related to year of establishment, classification of organization and number of employees are reported in Table II. More than three-quarter of the total organization respondents (87.8\%) were established in the minimum of 6 to more than 10 years and $12.2 \%$ had been operating between 2 to 5 years, none of the organization established less than 1 year. The result shows that most of the participated organizations in the study in this region are well established in logistics industry.

TABLE II: YEAR OF ESTABLISHMENT, CLASSIFICATION OF ORGANIZATION AND NUMBER OF EMPLOYEES

\begin{tabular}{lll}
\multicolumn{3}{c}{ AND NUMBER OF EMPLOYEES } \\
\hline Characteristics & Frequency & Percentage \\
\hline Year of establishment & 0 & 0 \\
Less than 1 year & 5 & 12.2 \\
2-5 years & 4 & 9.8 \\
6-10 years & 32 & 78 \\
More than 10 years & & \\
Classification of organization & 3 & 7.3 \\
Local authority & 20 & 48.8 \\
Manufacturer & 7 & 17.1 \\
Logistics service providers & 2 & 4.9 \\
Port operator & 9 & 22 \\
Other logistics users & 7 & 56.1 \\
Number of employees & & 17.1 \\
Less than 50 & 23 & \\
51-100 & 7 & \\
101-300 & & \\
More than 300 & & \\
\hline
\end{tabular}

Table II also shows the classification of the organizations. As explained earlier, the respondents consist of five clusters. Nearly $49 \%$ of the respondents were from manufacturer cluster. About $22 \%$ were from other logistics users. LSP cluster recorded $17.1 \%$ and $7.3 \%$ of the respondents were from local authority cluster. Only $4.9 \%$ of the total respondents were from port operator cluster. As far as number of employees was $73.2 \%$ of respondent's organization employed below than 100 employees; and $9.8 \%$ and $17.1 \%$ employed between 101 to 300 employees and more than 300 employees respectively. In term of type of organizations, the percentage respondents involved in this study were local company (LC) (63.4\%), government-link 
companies (GLC) (17.1\%), foreign company (FC) (14.6\%) and foreign-local joint venture company (FLJV) (4.9\%) as presented in Table III. Most of the respondents either have direct or indirect involvement in logistics service including distribution and warehousing activities except the local authorities who in-charge in the planning, development as well as the implementation of the government policy.

\begin{tabular}{lll}
\multicolumn{2}{c}{ TABLE III: TYPE OF ORGANIZATION } \\
\hline Characteristics & Frequency & Percentage \\
\hline Type of organization & 7 & 17.1 \\
Government-link company & 2 & 4.9 \\
Foreign-local joint venture & 2 & 14.6 \\
Foreign company & 6 & 63.4 \\
Local company & 26 & \\
\hline
\end{tabular}

\section{B. Current Logistics Infrastructure}

Table IV shows the satisfaction level of current logistics infrastructure in this region under this study. Almost three-quarter of the respondents $(73.2 \%)$ were satisfied with the current logistics infrastructure whereas $26.8 \%$ of the respondents were unsatisfied.

\section{TABLE IV: LEVEL OF SATISFACTION}

\begin{tabular}{lc}
\hline Item & Percentage \\
\hline $\begin{array}{l}\text { Respondents satisfied with current } \\
\text { logistics infrastructure }\end{array}$ & 73.2 \\
$\begin{array}{l}\text { Respondents unsatisfied with current } \\
\text { logistics infrastructure }\end{array}$ & 26.8 \\
\hline
\end{tabular}

Two profiles of respondent's organization were further examined in order to look into detail on the level of satisfaction and dissatisfaction of the current logistics infrastructure. As shown in Table V, the result between year of establishment and level of satisfaction shows that the organization operating less than 5 years were satisfied but between 6 to 10 years were equal. As for those organization which established more than 10 years, near to three-quarter $(71.9 \%)$ were satisfied with the current logistics infrastructure in this region and about $28.1 \%$ were unsatisfied.

The significant result above emphasized that ECR has good logistics infrastructure which agreed by the organization established in this industry for less than 10 years. It shows the logistics players have encountered fewer problems. Overall they have easy access of transportation deliver and receive their goods timely. However, the result also shows that the longer the organization operating in this region, the unsatisfied level increased gradually. However, due to small size of data, this study fails to see this trend. Furthermore, the finding shows respondents preferred to choose middle points which indicated that they were still uncertain on the level of satisfaction for the current logistics infrastructure especially in seaport transportation, rail network and road condition.

In terms of type of organization, result obviously shows that regardless of type of organization, the respondents were satisfied with the current logistics infrastructure in this region. Among the organizations, the FC was the highest score of unsatisfied with the current logistics infrastructure. Further analysis shows that respondents that dissatisfied representing organizations that have business experienced with other countries before they expanded their business in this region.

\begin{tabular}{|c|c|c|}
\hline $\begin{array}{l}\text { Year of } \\
\text { establishment }\end{array}$ & $\begin{array}{l}\text { Satisfied with } \\
\text { current logistics } \\
\text { infrastructure }\end{array}$ & $\begin{array}{l}\text { Unsatisfied with } \\
\text { current logistics } \\
\text { infrastructure }\end{array}$ \\
\hline & Frequency & Frequency \\
\hline $2-5$ years & $5(100 \%)$ & $0(0 \%)$ \\
\hline $6-10$ years & $2(50 \%)$ & $2(50 \%)$ \\
\hline$>10$ years & $23(71.9 \%)$ & $9(28.1 \%)$ \\
\hline \multicolumn{3}{|c|}{ Type of Organization } \\
\hline GLC & $5(71.4 \%)$ & $2(28.6 \%)$ \\
\hline FLJC & $2(100 \%)$ & $0(0 \%)$ \\
\hline $\mathrm{FC}$ & $4(66.7 \%)$ & $2(33.3 \%)$ \\
\hline $\mathrm{LC}$ & $19(73.1 \%)$ & $7(26.9 \%)$ \\
\hline
\end{tabular}

\section{Constraints of Logistics Industry}

Table VI shows the constraints in the logistics industry. Results indicated that main constraints for logistics industry as perceived by respondents were LI, LR and LP (their mean scores were over 3.40). Most respondents agreed that lack of logistics infrastructures would be affected the logistics development, lack of research in the logistics would slower down the logistics development and lack of professionalism in logistic industry were among the top logistics constraint in this region. This result supports the study by [10].

In contrast, the least critical constraints in the logistics industry were LF and GP (their means score below 3.35). This shows that the country provides the financial resources but might be with some limited provisions and most respondents were satisfied with the current government policy in developing the logistics industry.

TABLE VI: CONSTRAINTS OF LOGISTICS INDUSTRY Descriptive statistics

\begin{tabular}{lll} 
Items & Mean & Std. Deviation \\
\hline LI & 3.58 & 0.95 \\
LR & 3.49 & 0.84 \\
LP & 3.44 & 0.83 \\
LF & 3.30 & 0.90 \\
GP & 3.10 & 0.89 \\
\hline
\end{tabular}

In terms of standard deviation among items, the highest deviation of 0.95 was observed for LI. This finding shows the highest variation in the respondent's responses among the other items. On the contrary, the lowest variation was observed for item LP (0.83). Looking at the high standard deviation amongst items, respondent's variation in their answers is expected.

Overall, $78 \%$ of respondents were agreed on the above 
constraints of logistics industry in this region. This finding is instructive, it urges the relevant stakeholders to take an immediate actions in order to improve the logistics systems. These constraints must be resolved by the relevant stakeholders before realization or aspiration to become a competitive logistics hub in this region. Whereas, there were $22 \%$ of respondents disagreed.

\section{Challenges of Logistics Industry}

Table VII shows the descriptive statistics of the challenges in the logistics industry. The result shows that the mean score above 3.90 were for MAN and COS item - 3.95 and 3.90 respectively. Skilled manpower and logistics cost are among top items were found from the previous study as the challenges in the logistics development [5], [10], [11], [13], [16]-[18], [22].

The other three items for mean score of MKT, ATT and COM were within $3.50-3.89$. Among the items under this variable, the two highest standard deviations were observed for MAN (1.00) and COM (0.97). In contrast, the lowest standard deviation was for item COS (0.83). It shows that high variation in responses among respondents.

TABLE VII: CHALLENGES IN THE LOGISTICS INDUSTRY Descriptive statistics

\begin{tabular}{lll} 
Items & Mean & Std. Deviation \\
\hline MAN & 3.95 & 1.00 \\
COS & 3.90 & 0.83 \\
MKT & 3.68 & 0.88 \\
ATT & 3.62 & 0.89 \\
COM & 3.58 & 0.97 \\
\hline
\end{tabular}

Overall result shows $90.2 \%$ of respondents were agreed with the above challenges of logistics industry in this region. Despite the potential growth of the industry, the logistics players in this region have identified various challenges to be faced in future. Whereas there were $9.8 \%$ respondent were disagreed.

\section{CONCLUSION}

This study evaluated logistics development which amongst others includes the logistic infrastructure, constraints and challenges in Peninsular Malaysia East Coast Region. The overview of the current logistics development in which consists of infrastructure in this region provides several insights into the present situation of the industry. The review of constraints and challenges by the respondents and from the literature reflected the fragmented nature of the logistics industry.

Most respondent were satisfied with current logistic infrastructure in the region except fewer infrastructure such as the access to the seaport and rail network. This is because they are still unhappy with the infrastructure of seaport transportation, rail network and road condition. In terms of road condition, it was not acceptable to users as there were potholes, this is further compounded with dust which would risk to the logistics players and public users.

Although participants satisfied with the facilities, majority the logistics players faced the bunch of constraints in developing the logistics in this region as there are still lacking in logistics infrastructures, research, professionalism which involved the mind setting of the people and financial issues. It was similar to the causes of lack of manpower skill as most of the professional would not prefer to move from the big city to this region and the demand for talent outstripped supply. As result, the shortage of manpower will be a main constraint and challenge in developing effective and efficient logistics systems in this region. In addition, the increasing logistics costs over the past few years together with other issues continue to be constraints and challenges to develop the logistics industry in the region.

\section{ACKNOWLEDGEMENTS}

Authors are very thankful to the Universiti Malaysia Kelantan for the financial support through the Short Grant Research Scheme to carry out this study.

\section{REFERENCES}

[1] Regional Economic Corridors. [Online]. Available: http://www.mida.gov.my/env3/index.php?page=regional-economic-co rridors

[2] East Coast Economic Region (ECER). [Online]. Available: http://www.ecerdc.com.my/ecerdc/

[3] J. H. Bookbinder and C. S. Tan, "Comparison of Asean and Eropean logistics systems," International Journal of Physical Distribution \& Logistics Management, vol. 33, no. 1, pp. 36-58, 2002.

[4] Germany Trade \& Invest. (2010). Germany: Europe Logistics Hub. [Online]. Available: http://www.gtai.de/GTAI/Content/.../germany-europe-s-logistics-hub. pdf

[5] Li \& Fung Research Centre. (2008). China's logistics industry. (2007-2008). China Distribution \& Trading. [Online]. Available: http://www.lifunggroup.com/eng/knowledge/research/china_dis_issue 53.pdf

[6] M. Goh and C. Ling, "Logistics development in China," International Journal of Physical Distribution \& Logistics Management, vol. 33, no. 10, pp. 886-917, 2003.

[7] S. P. Sgouridis, "Freight transportation in Malaysia: Technological and Organizational issuees from an ITS perspective," AY 2002/2003 Spring Inception Report, June 30, 2003.

[8] Y. C. Thong, Overview the logistics industry in the Northern Region \& the need to enhance its effectivemness and competitiveness, Penang, July 5, 2007.

[9] KTM KARGO. (2010). [Online]. Available: http://www.ktmkargo.com/\#/our-service

[10] R. Ali, H. S. Jaafar, and S. Mohamad, "Logistics and supply chain in Malaysia: issues and challenges," in Proc. EASTS International Symposium on Sustainable Transportation incorporating Malaysian Universities Transport Research Forum Conf. 2008 (MUTRFC08), Universiti Teknologi Malaysia, 2008, pp. 1-11.

[11] N. Dekker, “Gold rush!” Containerisation International, vol. 35, no. 1, pp. 29-31, 2002.

[12] J. R. Carter, J. N. Person, and L. Peng, "Logistics barriers to international operations: the case of the People's Republic of China," Journal of Business Logistics, vol. 18, no. 2, pp. 129-145, 1997.

[13] W. K. Siew, "Developing Singapore into a global integrated logistics hub, report on the working group on logistics," ERC Working Group on Logistics, 2002.

[14] McKinsey and Company. (2011). Logistics industry challenges. McKinsey Solutions. [Online]. Available: http://solutions.mckinsey.com/logos/default/en-us/about/challenges.as px

[15] F. C. Chin, J. H. Bae, and G. O. Kim. (2010). A Survey on the logistics service providers in Shanghai. [Online]. Available: http://rightsite.asia/en/article/survey-logistics-providers-shanghai

[16] C. Thomaz. (2009). Growing logistics costs as constraint to trade. [Online]. Available http://www.engineeringnews.co.za/article/logistics-the-bread-and-ban e-of-southern-africa-trade-2009-06-05 
[17] Armstrong \& Associates. (2004). Ten key challenges for the Chinese logisticsindustry. [Online]. Available: http://www.globalautoindustry.com/article.php?id=175\&jaar=2005\& maand $=10$ \& target $=$ China

[18] L. Pomlett. (2006). The challenge of the east, viewed September, 15, 2011.

[Online].

Available: http://www.supplychainstandard.com/liChannelID/12/Articles/225/Th e+challenge+of+the+East.html

[19] L. J. Cronbach, Essentials of Psychological Testing, $5^{\text {th }}$ Ed. New York, Harper Collings Publishing, 1990.

[20] J. C. Nunnally and I. H. Bernstein, Psychometric Theory, $3^{\text {rd }}$ Ed. Mc Graw-Hill, New York, 1994.

[21] J. F. Hair, R. F. Anderson, R. I. Tatham, and W. C. Black, Multivariate Data Analysis, $5^{\text {th }}$ Ed. Prentice Hall International Incorporations, Upper Saddle river, New Jersey. USA, 1998.

[22] M. A. Razzaque, "Challenges to logistics development: the case of a Third World Country - Bangladesh," International Journal of Physical Distribution \& Logistics Management, vol. 27, no. 1, pp. 18-38, 1996.

A. A. Zuraimi is a senior lecturer in Faculty of Entrepreneurship and Business, Universiti Malaysia Kelantan. He has a master in Management and a bachelor degree in Business Administration (Hons.). He is also a chartered member of The Chartered Institute of Logistics and Transport (CMILT). His main areas of research interest are logistics management, supply chain management, strategic management, operations management and port, shipping \& maritime transportation management. He has a total of almost 15 years of working experience in industry before joining the academic field. $\mathrm{He}$ spent almost 10 years in Oil \& Gas and Petrochemicals companies, managing strategic planning, business development and trading, export and import management, commercial shipping and maritime transportation, supply chain management and logistics activities which consist of planning, sales \& procurement, operations, chartering and commercial. He was the head in strategic planning, commercial shipping and logistics department with Oil \& Gas and Petrochemicals companies and he focused on clean product petroleum, petrochemicals product including aromatics and olefin and gas. Prior to that, he gained valuable experiences in port and customs procedures when he was attached with Malaysian Ports and Malaysian Customs.

Mohd Rafi Yaacob is a Ph.D. He is also an associate professor at the Faculty of Entrepreneurship and Business, Universiti Malaysia Kelantan. Currently, he is the deputy dean on research and innovation at the faculty. He graduated from the Geography Department, University of Malaya in 1991 and worked as a tutor at the department from 1991 to 1994 . He pursued an MBA at the Middlesex University Business School (MUBS), United Kingdom in 1995 to 1996. He pursued Ph.D. at the Central Coast School of Business and Law, University of Newcastle, New South Wales, Australia in 2004 to 2007 under the International Postgraduate Research Student (IPRS) of the university. He earned Post graduate Diploma in Entrepreneurship (PGDE) from the University of Cambridge, United Kingdom in early 2013. His cores academic teachings include entrepreneurship, research methodology and strategic environmental management. He is actively engaged in research projects on small medium enterprises (SMEs), strategic management, green business as well as corporate environmentalism. He has presented papers in national and international seminars, published articles in refereed journals, authored and co-authored of academic and motivational books. He is also a member of editorial advisory boards and reviewer of several national and international academic journals.

Mohamed Dahlan Ibrahim is a Ph.D, and he is currently the professor of Entrepreneurship Education and Enterprise and the dean of Faculty of Entrepreneurship and Business at Universiti Malaysia Kelantan (UMK). Before joining UMK, he is an associate professor of Finance \& Economics at the Malaysian Entrepreneurship Development Center (MEDEC), Universiti Teknologi MARA (UiTM) Shah Alam. Prior to joining MEDEC in 1986, he has served as a traffic officer for Klang Port Authority from 1981 to 1982 . He was then awarded scholarship under the Young Lecturer Scheme to pursue his bachelors and master degrees in the USA. At MEDEC, his responsibilities include the planning and implementation of entrepreneurship programmes for UiTM students. He has also been awarded full scholarship to continue his studies at the Ph.D. level in 1994. He has also received the Excellent Service Award for Academician from the university in 1994. He has been conferred doctor of philosophy on May 1, 1998 when he successfully defended his dissertation entitled "Adoption of Project Appraisal Practice and Accessibility of Finance: An Empirical Analysis on Selected Small and Medium-sized Manufacturing Companies in Malaysia" by University of Stirling, United Kingdom. His field of expertise in addition to teaching financial management courses for Small and Medium Sized Industries (SMIs) include research and consultancy works primarily in the domain of strategic financial management and project appraisal for private and public financed projects. He has published over 50 research articles, authored and co-authored 12 books and supervised more than $10 \mathrm{Ph} . \mathrm{D}$. students of which more than 4 have graduated. He is also a chartered member of The Chartered Institute of Logistics and Transports (CMILT). 